\title{
Construction of Quality Assurance System for the Postgraduate Training
}

\author{
Xiaojun Zhang \\ College of Chemical Engineering, Northeast Electric Power University, Jilin 132012, China
}

\begin{abstract}
As the main body for quality assurance of postgraduate training, the college's quality assurance work runs through the entire process from enrollment to degree awarding, and is at the forefront of the entire postgraduate education quality system. And it was necessary to reform the evaluation mechanism and establish quality guarantee system. Actively promote the characteristics and advantages of disciplines, and standardize recruitment and retest selection procedures. Reasonable divide graduate training phases and links, and grasp the progress and quality of key links. Strengthen academic exchanges, provide a good academic atmosphere, and create a high-quality academic platform. Build a scientific, standardized, practical and efficient graduate reward and incentive mechanism. Further improve the selection system and appraisal procedures for the postgraduate student tutors, strengthen the tutor accountability system, and build a graduate tutor team with excellent quality and solidarity.
\end{abstract}

Keywords-Quality assurance system; Postgraduate training; Selecting procedures; Academic platform; Tutor accountability system

\section{INTRODUCTION}

Postgraduate education is the highest level in China's higher education structure. It is also an elite education in the popularization of higher education. It is responsible for cultivating high-quality talents, developing science and technology. With the rapid expansion of the enrollment of graduate students, the quality of their training has also received unprecedented attention. Therefore, it has become a problem that is strengthening the construction of quality assurance system for postgraduate education and effectively improving the quality of postgraduate education ${ }^{[1-3]}$. In January 2005, the "Opinions of the Ministry of Education on Implementing Postgraduate Education Innovation Program to Strengthen the Cultivation of Postgraduates' Innovative Ability and Further Improve the Quality of Training" clearly stated that "the emancipation of the mind and the updating of concepts are the preconditions, and the improvements of postgraduates' innovative awareness and ability are the core. Optimize resource allocation; stimulate the enthusiasm and creativity of postgraduates, tutors, and management cadres. Promote the profound reform of postgraduate training mode and mechanism; further improve the training conditions, and continuously improve the quality of training." This symbolized the construction of Chinese postgraduate training quality assurance system. It has entered a new era of cultivating mechanism reform and implementation of innovative plans as its main features. In July 2010, the
National Medium and Long-term Education Reform and Development Plan (2010-2020) clearly stated that "it was necessary to establish national standards for education quality and establish education quality assurance systems" ${ }^{[4]}$. In 2013, the Ministry of Education, the National Development and Reform Commission, and the Ministry of Finance jointly convened a nationwide postgraduate education work conference to initiate a comprehensive reform of postgraduate education, marking that the development of postgraduate education in China has entered a new historical stage ${ }^{[5]}$. The "Opinions on Deepening the Reform of Postgraduate Education" pointed out that classifying and promoting the reform of training mode and the overall construction of the quality assurance system are two important focal points for deepening the reform of postgraduate education. And it was necessary to reform the evaluation mechanism and establish quality guarantee system based on training units

\section{IMPORTANCE OF CONSTRUCTION}

With regard to the construction of the quality assurance system for graduate student training, our university clearly stated in the document "The 13th Five-Year Plan for Quality Improvement of Postgraduate Education" that comprehensively improving the quality of postgraduate education is the core task of deepening the reform of postgraduate education. It is of great significance to enhance the competitiveness of our university and nurture the innovative talents needed for national economic and social development. Further improve the quality assurance system, strengthen the awareness of quality, strengthen process management and supervision, and form an atmosphere that attaches importance to the quality of postgraduate training, internal quality feedback and continuous improvement mechanisms. The quality assurance work of postgraduate training should be based on the promotion of the overall development of postgraduates, and the formation of a two-tier education quality management mechanism with schools and colleges as the internal level. The school is responsible for the top-level design of the internal quality assurance system. The main functions are management, coordination, supervision, and self-assessment. The college is responsible for the development planning of the discipline or specialty, as well as the management, coordination, and execution of the college's internal education quality-related issues. 


\section{CONSTRUCTION OF THE SYSTEM AND CONTENT}

A. Actively promote the characteristics and advantages of disciplines, standardize recruitment and retest selection procedures, and establish a quality assurance sysytem for students.

The quality of students is the starting point for the construction of quality assurance mechanisms for graduate students. It is necessary to attach great importance to quality assurance links such as admissions promotion, selection methods, management, and retesting. Admission promotion is the prerequisite for student quality assurance; selection method and re-examination assessment are the core content of student source quality assurance; management and policy are the driving force of student source quality assurance.

\section{B. Reasonable division of graduate training phases and links,} grasping the progress and quality of key links, and regular supervision.

The improvement of the quality of postgraduate education can be achieved through the rational division of graduate training stages and links, process control, quality supervision, and continuous improvement. According to the actual situation of the college graduate training, the graduate training process is divided into three stages. The first stage is the stage of curriculum learning, including the determination of research direction, the development of learning plans, getting credits for study courses, and research preparation. The second stage is the research phase of the project, including the opening examination and the mid-term examination. The third stage is the thesis writing and the thesis defense stage, including the review of the qualifications of the defense and the organization of the defense. Dividing the training phases and links will help the tutors and students understand the characteristics of the training sessions and arrange the time for the course study and the project research. For the teaching management department, they can make better use of stage characteristics of the postgraduate education, and strengthen the control and management of the quality of graduate education.

\section{Strengthen academic exchanges, provide a good academic atmosphere, and create a high-quality academic platform.}

Postgraduate students are the main force of the future national innovation system. Its most important quality is the quality of innovation. Its development goal is to become topnotch innovative talents. The cultivation of postgraduates' creative qualities requires a variety of approaches and cannot be separated from a good environment. The practice of postgraduate academic activities shows that academic activities provide a very suitable atmosphere, environment, opportunity and stage for the cultivation of postgraduates' creative qualities, and they have an irreplaceable role.

\section{Build a scientific, standardized, practical and efficient graduate reward and incentive mechanism.}

The formulation of postgraduate awards and incentive mechanisms must be reasonable. It is necessary to focus on cultivating postgraduates' innovative ability and innovative thinking, and play the orientation and funding functions so as to maximize the effectiveness of rewards and incentive mechanisms.

\section{E. Further improve the selection system and appraisal procedures for the postgraduate student tutors, strengthen the tutor accountability system, and build a graduate tutor team with excellent quality and solidarity.}

With the further advancement of the reform of the postgraduate training mechanism in China, the tutors have become more and more dominant in the graduate student training and management. The tutors as the first responsible person for postgraduate students play a decisive role in the growth of graduate students. The tutors are not only the disseminators of scientific and cultural knowledge, but also the shapers of students' perfect personality. They have direct responsibility for the quality of graduate education. Postgraduate students begin with the study at school. The tutor is responsible for the entire process of student development. The key to the management of the postgraduate training process is the tutor ${ }^{[6-7]}$. In order to fully mobilize the tutors' enthusiasm and initiative, it is necessary to gradually establish a graduate-oriented graduate training mechanism so that the tutor's rights, duties, and responsibilities are relatively equal.

\section{RESEARCH PROGRAM}

\section{A. Authors and Affiliations Build a quality assurance system for the source of the students}

The college should use various propaganda tools and opportunities to vigorously publicize the school's advantages in running schools, the characteristics of the disciplines, the research direction, and the level of academic leaders and instructors. So the college can increase the visibility of the school, enhance the attraction of the students and obtain high quality students. Adhere to the principles of fairness, impartiality and openness, standardize recruitment and retest selection procedures, improve the re-examination system for postgraduate enrollment, explore talent selection methods based on improving the quality of students, and strictly adhere to admission standards to ensure admission quality. On the basis of expanding the recommendation for exempt students, the examination of candidates' comprehensive quality and development potential will be strengthened and the implementation of the reform of the selection mechanism will be promoted. 


\section{B. Process control and quality supervision at each training stage}

In the first phase of the course, a graduate student education steering committee was set up by members of the College Professorship Committee to supervise the teaching of the curriculum and effectively strengthen the management of the graduate student training and guidance. According to the research direction of the discipline, the corresponding curriculum system structure should be optimized. The classroom teaching content and teaching methods should be enriched at the same time. The assessment mechanism for minor courses should be established. The second stage is the research phase of the project, including the opening examination and the mid-term inspection, and the establishment of a pre-examination and centralized review system. Attach importance to topic selection and examination of open items. Invite the experts from various disciplines to set up a review panel to examine whether the topic of the thesis is appropriate, whether the arguments are sufficient, and whether the implementation steps are feasible. Strengthen the mid-term inspections to fully understand the progress of the project research, and timely help graduate students to solve the problems encountered in the study of the project. Warn the poor performance of graduate students in a timely, or postpone their defense to ensure that the graduate student thesis can be completed according to plan. The third stage is the stage of essay writing and thesis defense, including the review of defense qualifications and the organization of the defense. Full-time master's thesis papers are reviewed outside the school. Graduation defenses are strictly controlled to guarantee the quality of postgraduate education.

\section{Build a high-quality academic platform}

Further promote the development of postgraduate academic activities, increase the academic quality and practical results of the activities, and strengthen the macrolevel guidance and investment. Strengthen the planning, coordination and guidance of postgraduate academic activities, and actively guide and vigorously support the development of academic activities of various postgraduates. Fully mobilize all aspects of the academy to create conditions and provide guarantees for the activities. Encourage graduate students to actively participate in various academic seminars. The college regularly organizes academic exchange activities. According to the actual situation of each profession, the college organizes the teachers to cooperate with universities, scientific research, and some business units to carry out some scientific research activities. Build a variety of academic exchange platforms, so that graduate students can actively participate in social practice activities and academic research. And the ways of thinking and academic viewpoints of the students are in line with society.

\section{Build a scientific, standardized, practical and efficient postgraduate rewards and incentive mechanism.}

Further improve school-level scholarships and state-level scholarship assessment rules, and scientifically and reasonably design the proportion of students' academic performance and scientific research performance during school time. Fully mobilize the enthusiasm of students; further improve schoollevel innovation fund project review, mid-term inspection and acceptance rules. Appropriately increase the proportion of student competition in the assessment of scholarships, and encourage graduate students to actively participate in various types of innovative competitions at the national, provincial, and university levels.

\section{E. Build a high-quality academic platform}

In the construction of the mentor team, we always adhere to the principle of "optimizing the structure, setting jobs according to needs, and selecting the best posts" and strictly implement the selection of mentors. Graduate tutors are required to have noble ideological and moral sentiments, rigorous academic attitudes, high academic attainments, and good physical and mental qualities. At the same time, they must also have the research foundation and funding required for graduate training, and be full of innovative spirit and teaching practice experience. In the process of student cultivation, the tutor is required to be responsible for the entire process of student development from the moment he and the student establish a teacher-student relationship. The tutor is responsible for guiding students in setting the research direction, electing course credits, formulating research plans, writing thesis, and cultivating personality qualities. Wait. Strengthen the training of young and middle-aged mentors, maintain the sustainable development of the mentor team, and continuously supplement the reserve forces for the continuous development of graduate education.

Emphasis is placed on the teachers with master's and doctor's degrees, and the proportion of the teachers with doctor's degrees is constantly increasing. Implement dynamic management methods for the selection and assessment of the tutors, and mobilize the enthusiasm of the teachers to the maximum extent possible. Establish and improve an open teacher management mechanism, establish a combination of dedicated and part-time teaching staff, and attract talents from multiple sources. Enrich the experts with international education background, industrialists with considerable theoretical level, scientific research institutes, and high-tech technological elites. Form a diversified, highly academic team of part-time tutors. Strengthen the business development and management of the tutors, adopt the "going out, inviting in" approach. Select the tutors to participate in corporate scientific research and practice activities, and learn about new technologies and new technologies in the industry through scientific research cooperation. Improve teachers' own application skills, and enrich teachers' engineering practice experience. 


\section{CONCLUSION}

Currently, the college of Chemical Engineering has two first-level disciplines (Chemical Engineering and Technology, and Environmental Science and Engineering), four secondary disciplines (Applied Chemistry, Environmental Engineering, Biochemical Engineering, and Chemical Engineering) and 122 full-time students. As the main body for quality assurance of postgraduate training, the college's quality assurance work runs through the entire process from enrollment to degree awarding, and is at the forefront of the entire postgraduate education quality system. Faced with the new requirements of our country's graduate education, how to ensure the quality of postgraduate training has become the focus of our college. And to build a scientific and reasonable postgraduate training quality assurance system has become the key to improving the quality of postgraduate education.

Faced with the country's need for high-level talents in the new stage of the new century, relevant universities should take the responsibility of cultivating highly qualified graduate students with innovation ability, learning ability, coordination ability, and organizational leadership. Strengthen the management and evaluation of training links and strive to improve the quality of training of the graduate students.

\section{ACKNOWLEDGMENT}

This work was supported by the Postgraduate Education and Teaching Reform Project of Northeast Electric Power University (YJG201705).

\section{REFERENCES}

[1] J. Q. Gao, H, Zheng, X. H. Qi, “ Establishment of inner quality assurance system of graduate education in universities based on the overall quality concept", Higher Education Forum, vol. 10, pp 105-108, October 2015. (In Chinese)

[2] Y. Hu, Xue Yang, " Quality management and quality evaluation for full time professional graduate education", Jouranl of Graduate Education, vol. 2, pp 66-70, April 2012. (In Chinese)

[3] Z. J. Xie, S. H. Zhu, “ The discussion on quality assurance mechanism of graduate education from the perspective of multi-center governance theory" Jouranl of Graduate Education, vol. 4, pp 102-107, April 2017. (In Chinese)

[4] Z. J. Wang, “ On establishing quality assurance system of graduate education and its improvement", Journal of Graduate Education, vol.1, pp. 1-6, February 2011. (In Chinese)

[5] Y. Q. He, " A study of innovation in the graduate education quality system in China by means of complex system analysis", Journal of Graduate Education, vol. 6, pp. 27-31, December 2014. (In Chinese)

[6] C. D. Qian, Y. Qian, C. Y. Zhang, "Enhancing process management to improve postgraduate training quality", Journal of Graduate Education, Vol. 6, pp. 41-43, December 2011. (In Chinese)

[7] W. H. Zhou, M. L. Li, "On the quality assurance mechanism of graduate education-based on university investigation", Educational Research, vol. 3, pp. 59-65, March 2013. (In Chinese) 